\title{
PATOLOGÍAS DE LA REALIDAD VIRTUAL: CIBERCULTURA Y CIENCIA FICCIÓN. TERESA LÓPEZ-PELLIZA. 2015.
}

Ana Lúcia Trevisan (Universidade Presbiteriana Mackenzie)

Recebido em 01 fev 2016. Ana Lúcia Trevisan - possui graduação em FFLCH - Curso: Aprovado em 22 mar 2016. Letras Português/ Espanhol pela Universidade de São Paulo (1988), mestrado em Letras (Língua Espanhola e Literatura Espanhola e Hispano-Americana) pela Universidade de São Paulo (1994) e doutorado em Letras (Língua Espanhola e Literatura Espanhola e Hispano-Americana) pela Universidade de São Paulo (2002). Atualmente é professor do Programa de Pós-Graduação da Universidade Presbiteriana Mackenzie. Tem experiência na área de Letras, com ênfase em Literatura Brasileira e Hispano-americana, atuando principalmente nos seguintes temas: literatura comparada, narrativa Latino-Americana contemporânea, fronteiras e identidades culturais, relações dialógicas do discurso histórico e do discurso literário e os limites do fantástico e do mitologismo. 
O VERSO E O REVERSO DA REALIDADE VIRTUAL

PATOLOGÍAS

DE LA

REALIDAD VIRTUAL

Cibercultura y ciencia ficción

TERESA LóPEZ-PELLISA

cibercultura y ciencia ficción (2015), apresenta a seus leitores uma ampla e aprofundada visão crítica a respeito das mais variadas formas de expressão da cibercultura e da ficção cientifica. Permite, ainda, um mergulho em teorias científicas

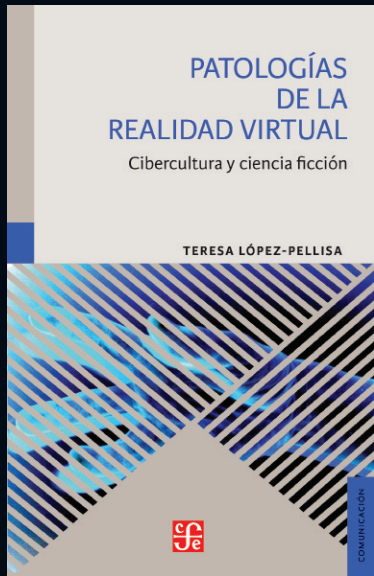
diversificadas, que abarcam diferentes áreas do conhecimento e instigam a reflexão sobre questionamentos humanos perenes. Ao longo do estudo surgem reflexões sobre cultura contemporânea, revelando algumas perguntas sem resposta que acompanham a humanidade em temporalidades diversas. Nesse sentido, a obra discute textos literários e produções fílmicas que indagam sobre a origem do Homem e do mundo conhecido, sobre o desejo da eternidade ou, ainda, sobre as proposições de um mundo perfeito.

Ao longo do texto de Teresa López-Pellisa, percebemos que as relações dos diferentes sujeitos históricos com a arte e com a imaginação ocupam o centro de sua pesquisa, no entanto, intermediando essas relações, surgem o pensamento científico e os produtos da tecnologia. Desta forma, gravitando ao redor do espectro, que envolve a imaginação e a ciência, observa-se a análise profícua daquilo que a autora nomeou de "patologia da realidade virtual". A leitura se torna interessantíssima justamente porquê cada uma das patologias assinaladas, representadas fortemente nas expressões da arte e da cultura, são ecos de experiências 
humanas vivas e cotidianas na atualidade. As obras literárias e os filmes que tratam da interação, a cada dia mais intensa, do homem com a realidade virtual, tornaram-se o espelhamento de um feixe de relações cotidianas que permeiam a vida de qualquer pessoa no século XXI. Não obstante, o estudo proposto apresenta, também, uma dimensão diacrônica dos efeitos da interseção das esferas do real e do virtual. Afinal, desde as narrativas míticas mais antigas até os relatos de ficção científica mais atuais é possível identificar a expressão de certos anseios que se alinham na forma de inquietações humanas.

No primeiro capítulo, quando a autora tece uma exaustiva explicação sobre os limites que envolvem a realidade virtual, é possível perceber a profundidade implícita na discussão que trata dos questionamentos a respeito do conceito de real. Afinal, o real é o que ocorre verdadeiramente? O virtual seria uma oposição ao real efetivo? A proposição dessas perguntas já anuncia a complexidade das muitas definições abordadas e, além disso, remete à experiência pessoal de todo e qualquer sujeito histórico que percebe sua imersão na virtualidade do real, ou nas múltiplas realidades virtuais. Teresa López-Pellisa conduz seu raciocínio resgatando as inquietações humanas manifestas desde o mito da caverna presente na República de Platão até o mundo virtual do filme Matrix (1999).

A imaginação humana já produziu formas estéticas de representação da realidade que anunciavam a presença dos mundos virtuais, haja vista os espetáculos teatrais, o teatro de sombras, as pinturas, o cinema, enfim, são muitas as formas de expressão da arte que, aliadas a tecnologias cada vez mais desenvolvidas, 
permitiram as múltiplas e surpreendentes expressões de realidade virtual. O que vemos, o que sentimos, ou o que percebemos do real significa uma experiência efetiva da realidade ou estamos imersos em um mundo engendrado pela imaginação ou pela invenção de outrem? Essa pergunta é uma dimensão dos questionamentos que nos propõem os estudos sobre as patologias da realidade virtual.

A primeira patologia destacada no texto trata, justamente, da "esquizofrenia nominal", que procura desvendar os usos e abusos dos vocábulos: virtual, ciberespaço e realidade virtual. Segundo a autora, os diferentes conceitos são fronteiriços nos seus significados, mas não devem ser usados indistintamente. 0 espaço virtual possui leis e dimensões espaço-temporais diferentes do espaço real e, para ingressar nesse espaço é necessário saber navegar em seus domínios, ou seja, exige-se iniciativa e esforço individual. No espaço virtual pairam certos riscos inevitáveis, denominados como "síndrome de Don Quixote", alusão explicita à perda de discernimento dos limites que separam o real do virtual.

O espaço digital para poder existir necessita da intervenção da tecnologia, pois sem a tecnologia informática, não seriam possíveis os espaços digitais. Dessa forma, o ciberespaço e a realidade virtual são uma categoria específica do que se denomina como virtual e poderiam ser bem definidos pela ideia de virtualidade digital. No espaço digital, mesmo prescindindo de uma conexão on-line, é possível submergir na realidade virtual. Dele podem surgir a vida artificial, o próprio ciberespaço, a realidade virtual, a realidade artificial, a realidade aumentada, a realidade alternativa, metaversos, a realidade sintética ou as realidades cruzadas, como enumera Teresa López-Pellisa. 
O ciberespaço, como esclarece a estudiosa, possui uma especificidade: é sempre um espaço digital que exige a conexão com alguma rede, ou seja, é preciso estar on-line para nos introduzirmos no ciberespaço. Do ciberespaço surgem diferentes tipos de virtualidade e interações, derivadas de diversas tecnologias e interfaces. Sempre que se conecta ao ciberespaço, entra-se em contato com o espaço digital.

Cabe a ressalva de que tudo o que propõem os espaços da virtualidade digital estão em sintonia com as propostas do mundo da ficção literária. Os sentidos da leitura e da literatura, nas suas manifestações imaginativas e interacionais, também descrevem as qualidades básicas para o funcionamento da realidade virtual. A imaginação, a imersão e a interação são chaves para o desenvolvimento de mundos artificiais, sejam eles literários ou marcados pela tecnologia. Logo, a imersão em contextos artificiais é uma característica compartilhada tanto pela literatura como pela tecnologia informática que repercute no espaço real.

A segunda patologia estudada é a "metástase dos simulacros", nela são analisadas e discutidas a proliferação cumulativa dos espaços virtuais e digitais. Tanto a literatura como o cinema podem oferecer diferentes níveis de virtualização e propiciar a experiência de diferentes contextos virtuais. Alguns textos propõem a experiência de espaços virtuais e digitais, desconcertando, assim, seus personagens e seus leitores que passam a duvidar de sua própria existência ou do espaço real no qual habitam. Nas análises literárias e fílmicas que compõem as explicações sobre a metástase dos simulacros, são apresentadas obras como: os romances $L a$ afirmación (1981) e Experiencias extremas S.A (1998) de Christopher 
Priest; os filmes Proyecto Brainstorn (1983), dirigido por Douglas Trumbull, Días extraños (1995), de Katheryn Bigelow e Sleep dealer (2008), de Alex Rivera, Simulacron-3 (1967), de Daniel F. Galouye, El mundo conectado (1973), de R.W. Fassbinder, Nivel 13 (1999), de Josef Rusnak, entre outros exemplos.

A terceira patologia é a "síndrome do corpo fantasma", que leva a um questionamento inquietante: estaríamos diante da obsolescência do corpo? Quando submergimos na realidade virtual, o corpo ocuparia o lugar de um paciente que, uma vez imerso na cultura high tech, será acometido por patologias que advém da sua inter-relação com o espaço digital. Pensar tais aspectos do corpo, significa rever a concepção do significado do Humano e, nesse ponto, a discussão de Teresa López-Pellisa tangencia os aspectos tecnológicos e éticos da biotecnologia. O corpo pode ganhar nova existência na realidade virtual quando mediado por aparatos tecnológicos, como luvas especiais ou capacetes com visores superpotentes, enfim, são as denominadas "próteses de hardware", mediadoras da interação entre o organismo de carne e osso e o espaço digital. O corpo não desparece, no entanto, pode, sim, ocupar o lugar de um corpo virtual, um simulacro perfeito para ações multissensoriais. Em contrapartida, toda essa modificação do corpo pode conduzir a percepção de que as máquinas também podem humanizar-se e, nesse aspecto, todas as relações homemmáquina ou máquina-homem, corroboram para redimensionar a concepção do ser humano. No âmbito dessa patologia, surge a análise do ciborg, do robô e do pós-humano.

A quarta patologia, "misticismo agudo", parte do desejo pela eternidade ou da esperança de imortalidade, ambições humanas que 
provocam efervescência no âmbito dos discursos científicos. A ficção científica, algumas vezes, parece ter se transformado em uma forma de seita milenarista, pois promete mundos de simulacros utópicos, anuncia novos "el Dorados", passíveis de serem encontrados em nosso tempo histórico. O "misticismo agudo" mantém uma relação estreita com a ideia do "corpo fantasma", pois a possibilidade de criar seres (artificiais, de silício) dotados de vontade e arbítrio, exemplifica a ideia de que poderes demiurgos podem ser concedidos aos homens. Esses novos seres aludem a uma nova humanidade, que poderia ser completamente aprimorada, logo, evidencia-se uma conduta mística e de sentimentos metafísicos que, ao serem transportados ao ciberespaço e a realidade virtual, ressurgem na forma de "sacerdotes de silício e pias batismais de puro hardware", como assinala a autora (LÓPEZ-PELLISA, 2015, p. 192).

A quinta e última patologia é a "síndrome de pandora", que pode ser observada nos muitos textos que tratam dos personagens femininos gerados artificialmente. A análise da autora resgata diferentes formas de reflexão sobre o feminismo e constrói uma discussão valiosa a respeito da objetualização do corpo feminino. As imagens femininas surgem, neste tipo de ficção, a partir do ponto de vista masculino, de seus fetiches. Apoiando-se nas ideias de Michel Foucault, a autora observa a presença de três figuras, exemplificadas pelo filósofo, nas ficções: a) o monstro humano, representado, nas ficções, pela imagem de homens que projetam seus fetiches e fantasias sexuais em mulheres simulacro, as quais existem, tão somente, para garantir o prazer do seu criador; b) o indivíduo a ser corrigido, ou seja, o louco e o criminoso com desvios sexuais, surge representado nos textos por suas "anomalias" de 
ordem sexual; c) o masturbador, que aparece em ficções nas quais o corpo feminino se manifesta no jogo da presença e da ausência, evidenciando a sexualidade que se manifesta sem a necessidade do contato com o outro corpo.

Nas ficções em que se surge a "síndrome de pandora" é possível identificar a presença dos mitos de Pigmaleão e Galatea e da figura de Narciso. O surgimento de uma mulher criada para agradar o seu criador, também remete às patologias destacadas anteriormente, como a "síndrome do corpo fantasma" e o "misticismo agudo". A criação dos simulacros corresponde ao desejo de manipular a vida, de controlar o destino, as relações sentimentais, o sexo e a reprodução. A humanização da máquina, levada aos extremos, conduz justamente a desumanização dos sujeitos. Movimento contraditório e singular, que parece permear as experiências virtuais no ciberespaço.

O mergulho nas obras de ficção científica, bem como o encontro com os contornos da cibercultura, garante uma avalanche de questionamentos. As projeções literárias e fílmicas tornam-se um espaço da arte que permite aos sujeitos históricos o encontro com a veleidade dos desejos e, ao mesmo tempo, a frustração com as mazelas dos sentimentos humanos. Em seu diálogo com o mundo, a arte bebe nas fontes da realidade, mas, tantas vezes, é a própria realidade que necessita das construções ficcionais para exprimir suas verdades mais contundentes. A arte transforma-se em uma grande provocadora, uma vez que pode caminhar pelos temas mais surpreendentes, rompendo direta ou indiretamente com as ideologias dominantes ou marginais, estabelecendo outros limites geográficos, podendo subverter expectativas e o senso comum. 